\title{
Treatment Outcomes of High-Risk Non-Muscle Invasive Bladder Cancer (HR-NMIBC) in Real-World Evidence (RWE) Studies: Systematic Literature Review (SLR)
}

\author{
Mihaela Georgiana Musat (D) ${ }^{1}$ \\ Christina Soeun Kwon' \\ Elizabeth Masters ${ }^{2}$ \\ Slaven Sikirica ${ }^{3}$ \\ Debduth B Pijush ${ }^{3}$ \\ Anna Forsythe ${ }^{4}$
}

'Evidence Generation, Purple Squirrel Economics, a Wholly Owned Subsidiary of Cytel, Inc., Waltham, MA, USA; ${ }^{2}$ Real World Evidence, Pfizer, New York, NY, USA; ${ }^{3}$ Global Health Economics and Outcomes Research, Pfizer, New York, NY, USA; ${ }^{4}$ Value and Access, Purple Squirrel Economics, a Wholly Owned Subsidiary of Cytel, Inc., Waltham, MA, USA
Correspondence: Mihaela Georgiana Musat Purple Squirrel Economics, a Wholly Owned Subsidiary of Cytel, Inc, 1050 Winter Street, Waltham, MA, 0245I, USA Email mihaela.musat@pshta.com
Background: To date, there has been limited synthesis of RWE studies in high-risk nonmuscle invasive bladder cancer (HR-NMIBC). The objective of this research was to conduct a systematic review of published real-world evidence to better understand the real-world burden and treatment patterns in HR-NMIBC.

Methods: An SLR was conducted following the Preferred Reporting Items for Systematic Reviews and Meta-Analyses (PRISMA) guidelines with the scope defined by the Population, Intervention Comparators, Outcomes, and Study design (PICOS) criteria. EMBASE, MEDLINE, and Cochrane databases (Jan 2015-Jul 2020) were searched, and relevant congress abstracts (Jan 2018-Jul 2020) identified. The final analysis only included studies that enrolled $\geq 100$ patients with HR-NMIBC from the US, Europe, Canada, and Australia.

Results: The SLR identified 634 RWE publications in NMIBC, of which 160 studies reported data in HR-NMIBC. The average age of patients in the studies was 71 years, and $79 \%$ were males. The rates of BCG intravesical instillations ranged from 3\% to $86 \%$ (29-95\% for induction and $8-83 \%$ for maintenance treatment). Five-year outcomes were $17-89 \%$ recurrence-free survival (longest survival in patients completing BCG maintenance), 58-89\% progression-free survival, $71-96 \%$ cancer-specific survival (lowest survival in BCG-unresponsive patients), and 28-90\% overall survival (lowest survival in patients who did not receive BCG or instillation therapy).

Conclusion: BCG treatment rates and survival outcomes in patients with HR-NMIBC vary in the real world, with better survival seen in patients completing maintenance $\mathrm{BCG}$, responding to treatment, and not progressing to muscle-invasive disease. There is a need to better understand the factors associated with BCG use and discontinuation and for an effective treatment that improves outcomes in HR-NMIBC. Generalization of these results is limited by variations in data collection, reporting, and methodologies used across RWE studies.

Keywords: real-world outcomes, high-risk NMIBC

\section{Introduction}

Bladder cancer is the tenth most common cancer globally. ${ }^{1}$ In the US, it was the sixth most common type of cancer overall in 2020 and was estimated to account for $4.5 \%$ of all new cancer diagnoses, with 81,400 new cases reported in 2020. Bladder cancer is approximately four times more common in men than in women, and the majority of cases are seen in persons aged over 55 years. ${ }^{2}$ The average 5 -year survival rate is approximately $77 \%$, which declines with greater degree of spread, from $95.8 \%$ for in situ disease to less than $6 \%$ with distant metastases. ${ }^{2}$ 
There are four main stages of disease, according to the Tumor, Node, Metastasis Classification (TNM), based on the degree of muscle involvement. ${ }^{3,4}$ TNM classification includes $\mathrm{T} 0$ as the first stage of the disease, when there is no evidence of primary tumor. Tumors staged Ta, T1, and/ or CIS are considered non-muscle invasive bladder cancer (NMIBC), where the tumor is localized to the inner lining of the bladder without involving deeper muscle layers. ${ }^{3,5}$ NMIBC accounts for over $70 \%$ of all bladder cancer cases. $^{6,7}$

Transurethral resection of the bladder tumor (TURBT) followed by 6 -week induction therapy with intravesical Bacillus Calmette-Guerin (BCG) is recommended by guidelines from the European Association of Urology (EAU), and American Urological Association and Society of Urologic Oncology (AUA/SUO) in patients with high-risk NMIBC (HR-NMIBC). ${ }^{3,4}$ There is some variability among guidelines with respect to the length of maintenance BCG therapy in high-risk patients; the NCCN and AUA/SUO recommend maintenance treatment for 3 years, ${ }^{3,8}$ whereas the EAU recommends BCG maintenance for 1-3 years, while noting that 3 -year maintenance therapy is more effective than 1 year in high-risk patients. ${ }^{3,4,8}$ Recommendations also differ slightly across guidelines on the use of repeated resection (re-TURBT). While reTURBT is recommended across all three organizations within 2-6 weeks following the initial procedure for $\mathrm{T} 1$ tumors, it is also recommended in high-risk, high-grade Ta tumors by the AUA/SUO; in high-grade Ta tumors after incomplete resection or if no muscle is present in the specimen by the NCCN; and also after incomplete resection or if no muscle is present in the specimen by the $\mathrm{EAU}$, except for low-grade $\mathrm{Ta} / \mathrm{G} 1$ or CIS tumors. ${ }^{3,4,8}$ Radical cystectomy is a morbid procedure involving complete excision of the bladder, which is reserved for patients at high risk of disease progression and who have not responded to BCG (EAU; AUA/SUO), or in patients with residual high-grade T1 disease (NCCN)., ${ }^{3,4}$

Patients with high-risk disease are at an increased risk of disease progression and mortality. ${ }^{9}$ Prognostic factors associated with high-risk disease have been proposed by the American Urology Association and Society of Urologic Oncology (AUA/SUA), as well as the European Organization for Research and Treatment of Cancer (EORTC) and the Spanish Club Urológico Español de Tratamiento Oncológico (CUETO). ${ }^{8,10,11}$ The risk stratification system from the AUA/SUA accounts for prior BCG therapy and classifies high-risk patients as those with highgrade $\mathrm{T} 1$ disease, variant histology, prior BCG failure, recurrent Ta disease, high-grade Ta tumor greater than $3 \mathrm{~cm}$ in size, and carcinoma in situ (CIS). ${ }^{8}$ Furthermore, the 2004 grading system from the World Health Organization/International Society of Urological Pathology (WHO/IUSP) associates high-grade disease with large tumor size, invasion of the lamina propria, $>\mathrm{T} 1$ stage, CIS, multiplicity, invasion, and metastasis. The WHO/ISUP states that a higher risk of disease progression, recurrence, and mortality is associated with highgrade versus low-grade disease. ${ }^{9}$

While there are a number of studies that have assessed the real-world effectiveness of therapies in NMIBC, there is a paucity of research that has synthesized this real-world evidence (RWE) in a systematic way. RWE is critical to understanding treatment patterns, and the effectiveness of therapies used in routine clinical practice. A systematic literature review (SLR) was conducted to gain a comprehensive and up-to-date understanding of the real-world use and effectiveness of current therapies used in NMIBC, with a specific focus on patients with HR-NMIBC. Understanding the characteristics of RWE studies (such as by study type, data source, intervention type, and sample size), data sources used, and type and frequency of the main outcomes reported were additional objectives of the SLR.

\section{Methods}

Searches were conducted in accordance with the Preferred Reporting Items for Systematic Reviews and MetaAnalyses (PRISMA) guidelines. The scope of the SLR was defined in terms of the PICOS criteria (Population, Intervention, Comparators, Outcomes and Study Design) and followed the principles outlined in the Cochrane Handbook for Systematic Reviews of Interventions, Centre for Reviews and Dissemination (CRD)'s Guidance for Undertaking Reviews in Health Care, and Methods for the Development of National Institute for Health and Care Excellence (NICE) Public Health Guidance. $^{12-15}$

The key biomedical literature databases (Medical Literature Analysis and Retrieval System Online $\left[\right.$ MEDLINE $\left.^{\circledR}\right]$, Excerpta Medica Database $\left[\right.$ Embase $\left.^{\circledR}\right]$ ), and Cochrane database (Collaboration databases), were searched via the Ovid platform between January 1, 2015 and July 2, 2020. The following conferences were searched for relevant abstracts published between 2018 and 2020: American Society of Clinical Oncology 
(ASCO), American Society of Clinical Oncology Genitourinary Symposium (ASCO GU), European Society for Medical Oncology (ESMO), and ISPOR.

Given the diverse nature of real-world studies, broad criteria were used to identify relevant publications. "Realworld" evidence encompassed: prospective observational studies, retrospective studies, registry analyses, database analyses, natural history studies, and non-interventional studies. Only studies involving at least 100 patients with NMIBC from the US, Europe, Canada, and Australia were selected due to the large number of hits. Geographic criteria were also added in order to limit the heterogeneity in the reported data. Case reports were excluded regardless of sample size. The patient population included those with NMIBC, early-stage bladder cancer, or stage 0 or 1 bladder cancer. There was no restriction with regards to comparators or outcome measures reported by studies.

Overall, the SLR included all relevant real-world studies in NMIBC. This report focuses on RWE studies that involved patients with HR-NMIBC. As there is no standardized definition for "high-risk" disease in the literature, wide criteria were adopted when assessing risk categories of studies identified in the SLR. Studies were only included if authors defined or specified that patients had high-risk disease. High-risk status was not assumed based on the treatment received, without it being indicated in the publication.

Weighted averages were used to describe patient characteristics, and treatment patterns were categorized by the percent range of reported treatment. A separate category ("100\%") was added for studies that included patients only treated with a certain type of therapy. In contrast, clinical outcomes were reported by individual study rather than using weighted averages or summary statistics due to the heterogeneity across RWE studies in HR-NMIBC.

\section{Results}

A total of 11,426 publications were identified from searches. Of these, 2879 were selected for title/abstract review, and 376 met the criteria for data extraction. Of these, 160 publications reported HR-NMIBC patient identification or outcomes and were included in this review (Figure 1). In 85 publications, HR-NMIBC comprised the total study population, and 75 publications reported outcomes in HR-NMIBC as a patient subgroup.

One hundred and sixty publications reported outcomes in or identified patients with HR-NMIBC. Regarding the definition of "high-risk" disease, 93 studies used criteria from guidelines to define high-risk. No specific criteria were mentioned in 20 studies and patients were identified by treatment received for high-risk disease (as identified by the publication). In 156 studies, disease category/staging was used to identify high-risk patients (not mutually exclusive; see Tables 1- $\underline{3}$ in the Supplementary Appendix).

Of the 160 identified publications, 141 specifically reported outcomes or treatment patterns in HR-NMIBC. The majority of real-world studies in HR-NMIBC identified in the SLR were retrospective (84\%), and half were single-center studies. Among the selected publications, the majority of studies were conducted in Europe (61\%), followed by the US (25\%), and other international countries $(11 \%)$. The number of patients enrolled varied across studies, with $62 \%$ including between 100 and 500 patients and $25 \%$ including over 1000 patients.

\section{Patient Characteristics}

Consistent with epidemiologic reports, the majority of patients with HR-NMIBC in real-world studies were males aged over 60 years, with a weighted average age of 71 years (range 65-86 years) and 79\% male gender (range 56-100\%).

Most patients had Stage 1 and/or high grade (HG) disease, according to the $2004 \mathrm{WHO} / \mathrm{ISUP}$ classification criteria (91\% and 92\%, respectively; Figure 2). A degree of heterogeneity in tumor characteristics was observed across the real-world literature. Multiple tumors were reported in $21-71 \%$ patients with HR-NMIBC, multifocality reported in $20-86 \%$, and large tumors $(>3 \mathrm{~cm})$ reported in $11-76 \%$ of the patients across studies. Tumors of variant histology were present in up to $25 \%$ of the patients.

\section{Treatment Patterns}

Sixty-one studies reported the use of BCG in patients with HR-NMIBC. ${ }^{16-76}$ In 43 of these studies (70\%), BCG was used in all patients (100\% treatment rate). ${ }^{16,17,19,21-38,40-}$ $44,46,49,51,54,56,57,61-63,65,68,69,72-76$ BCG therapy was an inclusion criterion for some of these studies, which contributed to this high rate. In the remaining 18 studies (30\%), the reported use of BCG instillations in HRNMIBC patients ranged from $3 \%$ to $86 \%$.$18,20,39,45,47,48,50,52,53,55,58-60,64,66,67,70,71$

Thirty-five studies reported on the use of BCG induction

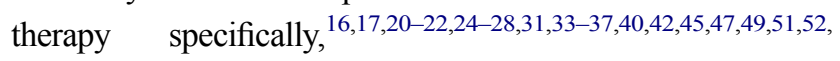




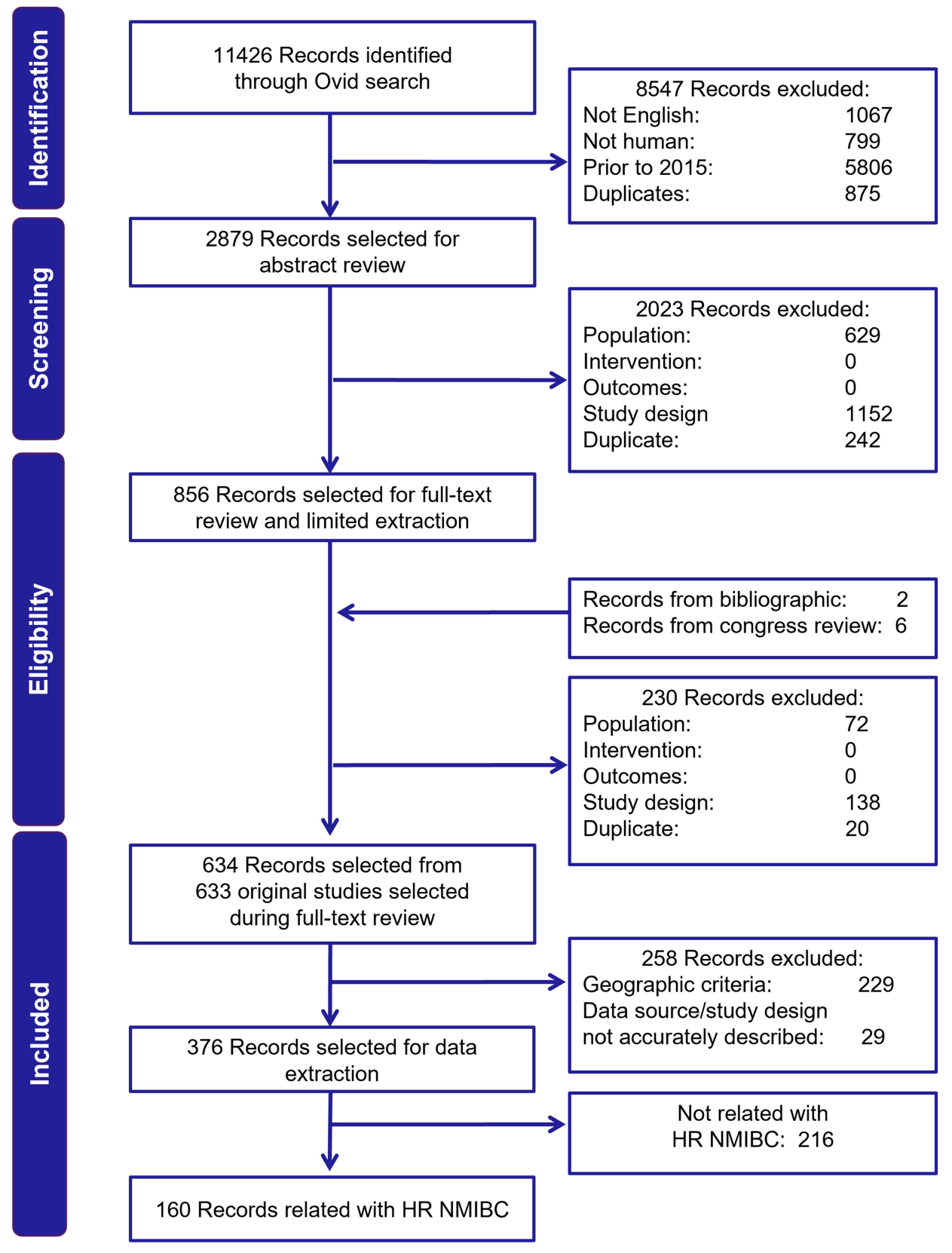

Figure I PRISMA flow diagram of the real-world SLR in NMIBC.

Abbreviations: HR, high-risk; NMIBC, non-muscle invasive bladder cancer; PRISMA, Preferred Reporting Items for Systematic Reviews and Meta-Analyses; SLR, systematic literature review.

$54,56,57,59,61,63,65,68,74,75,77,78$ of which $27(77 \%)$ reported the use of BCG induction in all patients $(100 \%) .^{16,17,21,22,24}$ 28,31,33-37,40,42,49,51,54,56,57,61,65,68,74,75,77 Among the remaining eight studies, rates of BCG induction therapy ranged from $29 \%$ to $95 \% .^{20,45,47,52,59,63,77,78}$ The use of maintenance BCG in HR-NMIBC was reported in 31 studies, with rates being more variable than those seen with induction therapy. ${ }^{16,17,26-}$ 29,31,33,34,36,37,40,42,45,46,49-52,54,56,59,61,63,65,68,69,72,74,75,77 Only 7 studies (23\%) reported BCG maintenance being used in all high-risk patients (100\%). ${ }^{26,28,29,40,49,56,61}$ Among the remaining 24 studies, use of maintenance BCG therapy ranged between $\quad 8-83 \%$. $^{16,17,27,31,33,34,36,37,42,45,46,50-52,54,59,63,65,68 \text {, }}$ $69,72,74,75,77$

Twelve studies reported the use of mitomycin $\mathrm{C}$ in high-risk patients. ${ }^{23,28,30,46,48,64,66,70,72,79-81}$ Treatment rates ranged from $2 \%$ to $53 \%$ in 9 studies, with few studies reporting its use in all patients (rate of $100 \%$ in 3 studies). In 7 of the 11 studies (64\%), mitomycin C 


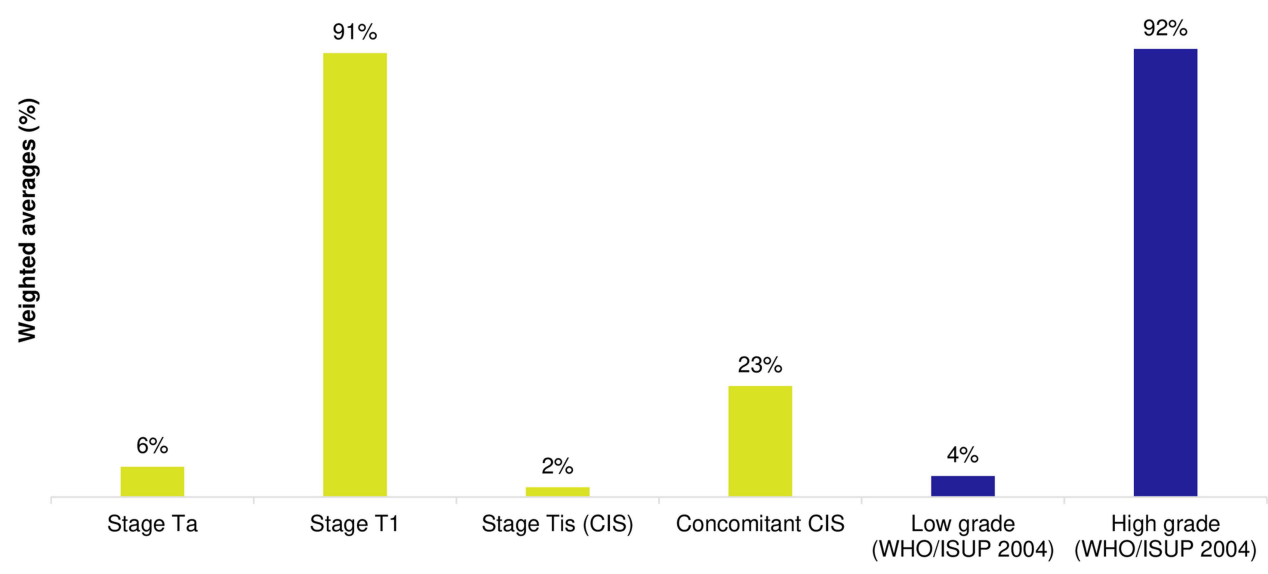

Figure 2 Tumor stages/grades reported in HR-NMIBC real-world studies (weighted-average \%).

Notes: Yellow bars represent the proportion of patients by tumor stage, whereas blue shading represents proportion by disease grade based on the WHO/ISUP 2004 system.

Abbreviations: Concomitant CIS, carcinoma in situ and Ta or TI; HR-NMIBC, high-risk non-muscle invasive bladder cancer; ISUP, International Society of Urological Pathology; WHO, World Health Organization.

was used in a minority of patients $(\leq 20 \%)^{23,28,46,48,64,66,72}$

Adjuvant and intravesical chemotherapy in HRNMIBC (not including mitomycin $\mathrm{C}$ ) were rarely used and reported in a small number of studies $\left(4^{55,58,66,67}\right.$ and $8,23,28,32,33,51,70,74,82$ respectively). The proportion of highrisk patients treated with adjuvant chemotherapy in reporting studies ranged from $2 \%$ to $19 \%$, and $4 \%$ to $34 \%$ for intravesical chemotherapy. The use of peri-operative chemotherapy was reported by only three studies and was generally used in less than a third of patients (range of $19-29 \%)^{37,42,58}$

The use of re-TURBT in patients with HR-NMIBC was reported in 43 studies. ${ }^{16,18-23,27-33,37,41-43,45,47,49-}$ 56,58,64,69,70,74,77,78,83-90 Across 27 studies, the use of this procedure varied from $15 \%$ to $82 \%,{ }^{16,18,20-22,30-33,37,41-}$ $43,45,47,49,50,52,53,55,58,70,74,77,83,86,87$ and in 16 studies, it was used in all patients $(100 \%){ }^{19,23,27-29,49,51,54,56,64 \text {, }}$ $69,84,85,88-90$

The use of radical cystectomy in HR-NMIBC was reported in 36 studies and rates likewise varied, ranging from $3 \%$ to $48 \%$ in 31 studies; ${ }^{20-22,30,32,41-}$ $43,50,53,55,57,58,65-67,70,71,76,81,86-88,91-98$ in the remaining 5 studies, radical cystectomy was used in $100 \%$ of the patients. ${ }^{47,99-102}$ Excluding these studies, $\leq 20 \%$ of the patients were treated with radical cystectomy in the majority $(60 \%)$ of studies.

Notably, a multicenter retrospective study conducted in Poland showed that following the diagnosis of HRNMIBC, $48 \%$ of the patients undergo restaging TURBT, $14 \%$ undergo intravesical $\mathrm{BCG}, 7 \%$ have radical cystectomy, and only $2 \%$ undergo intravesical chemotherapy with maintenance treatment, while the remaining $30 \%$ are managed under observation. ${ }^{55}$ Another Medicare database study showed a low incidence of aggressive treatment (radical cystectomy, radiotherapy, or systemic chemotherapy), with only $25 \%$ of the patients experiencing at least four recurrences undergoing radical cystectomy or radiotherapy within 10 years of diagnosis. ${ }^{92}$

Together, these findings indicate that BCG is a mainstay therapy commonly used in HR-NMIBC in real-world clinical practice settings, with the use of intravesical mitomycin $\mathrm{C}$, chemotherapy, and surgery being more variable and less common.

\section{Clinical Outcomes}

The 5-year progression-free survival (PFS), recurrencefree survival (RFS), cancer-specific survival (CSS), and overall survival (OS) real-world outcomes for patients with HR-NMIBC are presented individually by study in Figure 3. Patients completing maintenance $\mathrm{BCG},{ }^{34}$ responding to treatment, ${ }^{76}$ and not progressing to muscleinvasive disease ${ }^{88}$ have in general better survival.

\section{Five-Year Outcomes}

Five-year RFS rates were reported by 12 studies in the high-risk NMIBC population and ranged from $17 \%$ to $89 \%{ }^{16,27,36,37,41,42,46,54,72,81,103,104}$ The highest RFS rate was seen in a single-center study conducted in Spain in patients who completed BCG maintenance. ${ }^{34}$ Lower rates were seen in patients with high rates of disease recurrence and in those with a high disease burden, as based on the 


\section{A 5-Year RFS}

\section{Population (size) 5-Year outcome \%}

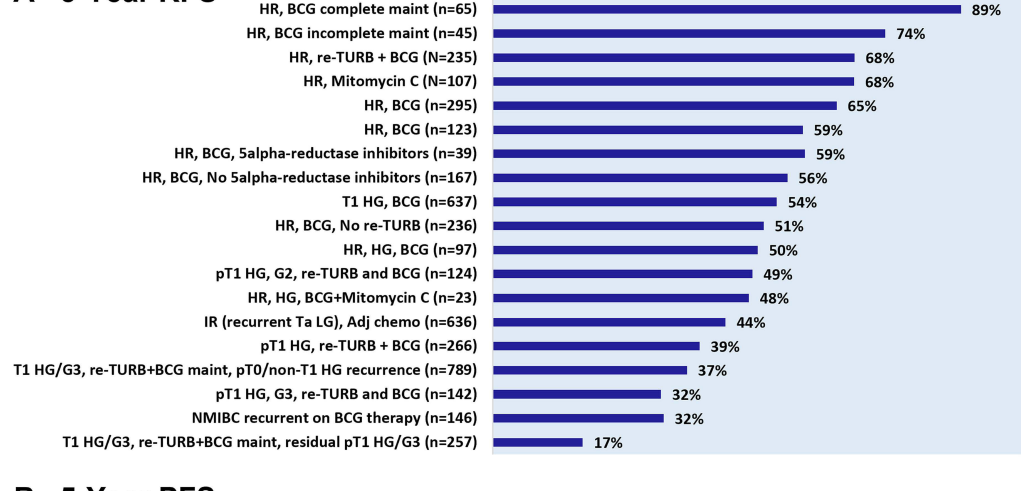

\section{B 5-Year PFS}

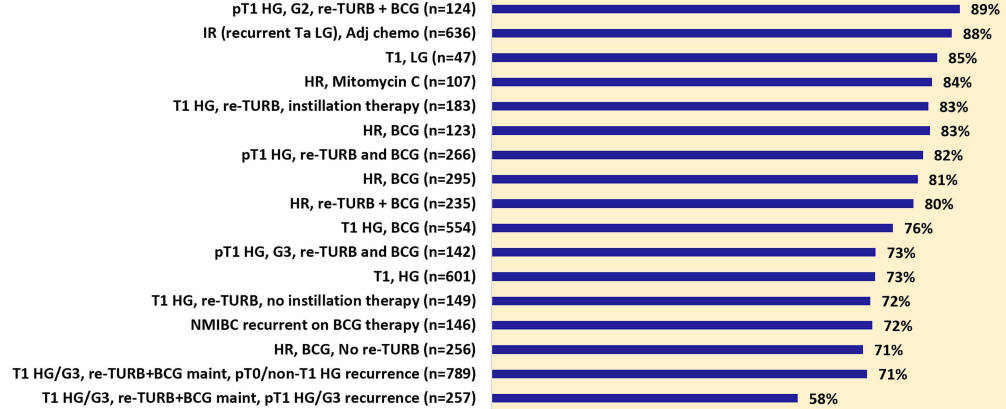

\section{5-Year CSS}

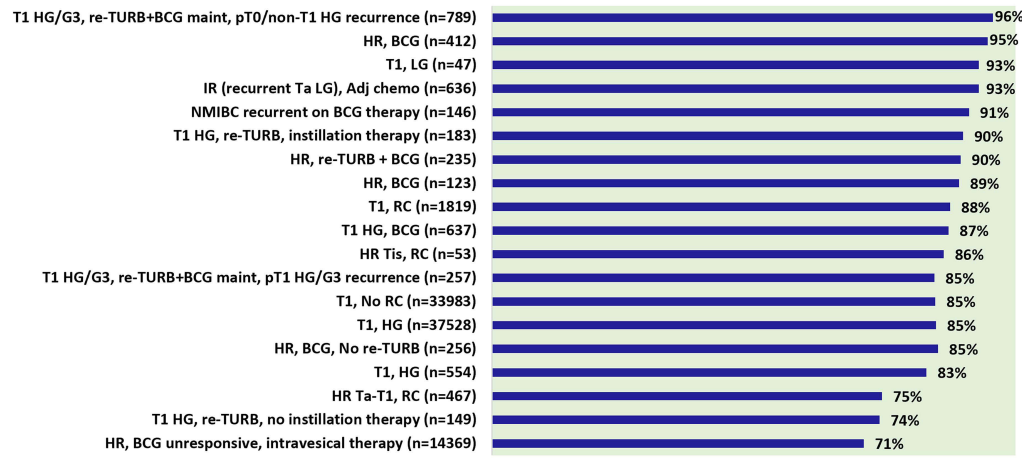

\section{5 -Year OS}



Figure 3 Five-year survival outcomes. Five-year survival outcomes for (A) recurrence-free survival (RFS), (B) progression-free survival (PFS), (C) cancer-specific survival (CSS), and (D) overall survival (OS).

Notes: These results for RFS, ${ }^{16,27,34,36,37,41,42,46,54,72,81,104}$ PFS, ${ }^{16,27,30,34-37,41,42,46,54,60,72,79-81,95,97,104,107}$ CSS, $^{27,37,41,42,46,73,76,88,94,98,102,104}$ and OS ${ }^{27,37,41,46,50,67,72,73,88,104}$ reflect the outcomes for high-grade disease as opposed to high-risk as few studies reported HR-NMIBC specifically, except for two studies that reported median OS results. Rates are presented as reported by individual study, they do not reflect weighted averages.

Abbreviations: BCG, Bacillus Calmette-Guerin; DOC, docetaxel; G2, grade 2; G3, grade 3; GEM, gemcitabine; HG, high-grade; HR, high-risk; IR, intermediate-risk; LG, low-grade; maint, maintenance therapy; NMIBC, non-muscle invasive bladder cancer; RC, radical cystectomy; TURB, transurethral resection of bladder tumor. 
need to undergo repeated TURBT or radical cystectomy. $^{27,46,54}$ The Spanish single-center study assessed outcomes among patients treated with different BCG strains due to a supply shortage of Connaught BCG at their clinic $\left(\right.$ Immucyst $\left.{ }^{\circledR}\right)$. Three treatment groups were evaluated: 1) Connaught group, 2) Tice (Onctice ${ }^{\circledR}$ ) group, and 3 ) induction Connaught followed by maintenance Tice group. Across the three groups, time to recurrence (TTR) ranged between 13 and 28 months and time to progression (TTP) between 16 and 46 months (no significant difference between groups). ${ }^{34}$ Patients with a history of NMIBC had significantly lower median TTR compared with those with primary NMIBC (11.9 vs 21.2 months) in a retrospective review of HR-NMIBC patients. ${ }^{78}$ Heavily pretreated patients receiving salvage therapy with gemcitabine and docetaxel after BCG failure, demonstrated a low median TTR of 6.8 months in a retrospective multicenter review. ${ }^{97}$ It is interesting to note that a study in HR-NMIBC patients with residual T1 high-grade G3 (HG/ G3) disease treated with re-TURBT and BCG maintenance reported the lowest 5-year RFS (17\%) of the 12 studies. $^{27}$

Five-year PFS rates were reported by 11 studies among the HR/IR NMIBC population, ranging from 58\% to $89 \%$. $^{27,36,37,41,42,46,54,81,88,98,104}$ Among the 11 studies, the lowest PFS rate of $58 \%$ was reported in the same population of patients with the lowest RFS rate (Ferro et al 2018), ie, those with residual T1 HG/G3 disease at re-TURBT. ${ }^{27}$ The study reporting the highest PFS rate was in a population of patients with pT1 G2 disease treated with re-TURBT and adjuvant BCG $(89 \%) .{ }^{54}$

Five-year CSS rates in HR-NMIBC patients were reported by 12 studies and ranged between $71 \%$ and $96 \%{ }^{27,37,41,42,46,73,76,88,94,98,102,104}$ The study reporting the lowest rate was in patients who did not respond to intravesical BCG. ${ }^{76}$ Two studies reported 10-year CSS, which was achieved in the majority of patients $(85 \%$ and $92 \%){ }^{32,73}$

Five-year OS rates were reported by 10 studies and ranged widely from $28 \%$ to $90 \%$. $^{27,37,41,46,50,67,72,73,88,104}$ Among the 10 studies, the lowest OS rate was reported in a study of patients with $\mathrm{T} 1 \mathrm{HG}$ disease who did not receive BCG or instillation therapy $(28 \%) .{ }^{50}$ Significantly lower 5-year OS was reported in one study in patients with T1 HG undergoing initial local treatment compared with those receiving early radical cystectomy $(52.4 \%$ vs $71.1 \%$; $\mathrm{p}<0.001) .{ }^{67} \mathrm{~T} 1 \mathrm{HG}$ disease at re-TURBT was also associated with lower survival compared with other NMIBC types of recurrence in the study by Ferro et al (74\% vs $90 \%)^{27}$

Ten-year OS was reported in only 2 studies and was $49 \%$ in HR-NMIBC patients ( $\mathrm{Ta} / \mathrm{T} 1 \mathrm{HG}$, majority treated with at least 6 doses of BCG) and $59 \%$ in T1 HG patients treated with complete induction and at least one dose of maintenance BCG. ${ }^{32,73}$

Event-free survival (EFS) is related to recurrence, disease progression, and survival. EFS was only reported by one study (with two publications) of patients with primary NMIBC or MIBC who underwent TURBT or radical cystectomy. $^{105,106}$ In these patients, EFS was $68 \%$ and $32 \%$, respectively.

\section{Time to Event Outcomes}

Median RFS/TTR was reported by 13 studies and ranged from 5.1 to 28.0 months ( 7 studies reported two or more values by subgroup). ${ }^{17,31,34,36,41,43,46,58,68,72,78,97,108} \mathrm{Six}$ studies reported median PFS/TTP, which ranged widely from 9.2 to 45.8 months (1 study reported PFS by three subgroups based on BCG type). ${ }^{17,34,36,58,68,87}$ Median CSS of 47.1 months was reported in only one study in HRNMIBC. ${ }^{17}$

Only one study was identified that proposed combination intravesical chemotherapy (gemcitabine and docetaxel) for the treatment of HR-NMIBC patients who failed BCG therapy. The median TTR was 6.8 months for the overall population and 9.5 months for patients who underwent subsequent cystectomy. ${ }^{97}$ Intermediaterisk (IR) patients treated with adjuvant chemotherapy (mitomycin $\mathrm{C}$, epirubicin, or doxorubicin) carried a high risk of recurrence (5-year RFS 44\%), but a lower risk of long-term progression (5-year PFS 88\%). ${ }^{104}$

Only two studies reported median OS in high-risk or high-grade NMIBC, ${ }^{67,109}$ of which one reported OS by treatment with radical cystectomy in high-grade NMIBC (Figure 4). ${ }^{67}$ In the case of patients with HR-NMIBC and T1 HG disease, early radical cystectomy was associated with longer median OS compared with patients not undergoing cystectomy and receiving endoscopic management, with or without intravesical therapy $(72.4$ vs 64 months; Figure 4). ${ }^{67}$ The lowest median OS was reported in the study of patients with high-risk disease specifically (median OS of 52.8 months), which classified high-risk as stage Ta, T1, or CIS (grade III [poorly differentiated]) or IV (undifferentiated); and tumor size $\geq 3 \mathrm{~cm}^{109}$ 


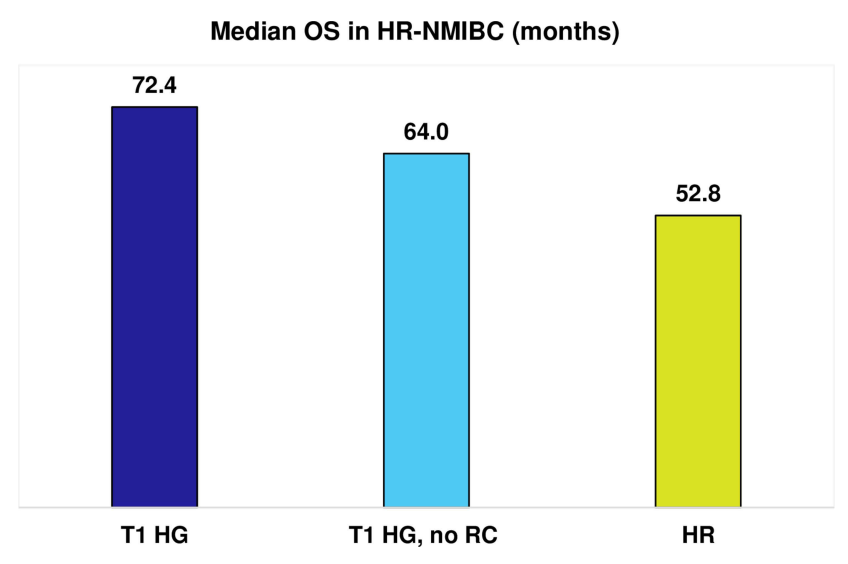

Figure 4 Median OS (months) in HR-NMIBC.

Notes: Median OS results are presented as reported by individual study, they do not reflect weighted averages. Data from these studies. ${ }^{67,109 .}$

Abbreviations: HG, high-grade; HR, high-risk; NMIBC, non-muscle-invasive bladder cancer; OS, overall survival; RC, radical cystectomy.

\section{Clinical Outcomes at Follow-Up}

The median follow-up for CSS ranged from 12 to 130 months across 30 studies that reported CSS at follow-up.$17,20-23,27,28,32,33,40-42,44,46,47,49,51,52,66,68,70,74,83,86-88,97-$

99,110 There was no observed trend in the proportion of HR-NMIBC patients dying due to cancer (CSS) with increasing length of follow-up (Figure 5A). Median follow-up for OS ranged from 23 to 130 months across the 21 studies that reported this. ${ }^{23,27,28,32,33,37,47,49,51,58,66,69 \text {, }}$ 70,74,83,86-88,97-99 Likewise, there was no evident trend in survival outcomes with increasing duration of follow-up. Notably, one study by Gordon et al reported the lowest percentage of patients who were alive at follow-up (9.8\%) out of the 21 studies, which was seen in patients with HRNMIBC who did not undergo re-TURBT after a median follow-up period of 50 months. ${ }^{86}$

Treatment discontinuation rates were primarily related to the proportion of patients completing maintenance BCG therapy. Studies showed that overall treatment compliance among high-risk patients is poor, with approximately half of patients completing maintenance therapy (ranging from $29 \%$ to $59 \%)^{17,37,40,63,103}$ In the overall NMIBC population, as few as $15 \%$ of the patients complete maintenance therapy. $^{111}$

\section{Discussion}

Findings from this SLR identified that treatment patterns and survival outcomes in HR-NMIBC are varied in realworld clinical practice. Due to the heterogeneity in outcomes measured and patient populations, it is difficult to accurately determine if real-world outcomes are consistent with clinical trial data. Nonetheless, in comparing against the landmark South West Oncology Group (SWOG) randomized trial, 5-year OS, PFS, and RFS with maintenance BCG were $83 \%, 76 \%$, and $60 \%$, respectively, ${ }^{112}$ which are largely in line with outcomes from several RWE studies identified in this SLR (Figure 3).

Various methods used across studies to identify and define high-risk patients contribute to the heterogeneity reported in the literature. The high-risk population included in studies was not always standardized in terms of disease stages and grades. While most studies agreed that T1 HG-disease is categorized as high-risk NMIBC, some also include other criteria such as Ta HG, Ta LG multiple recurrent tumors, multifocal, or large tumors.

Treatment guidelines recommend the use of adjuvant induction BCG after TURBT followed by maintenance $\mathrm{BCG}$, typically ranging from 1 to 3 years in patients with high-risk disease. ${ }^{3,4,8}$ Findings from this SLR showed there is no consistent approach to the treatment of HRNMIBC in the real-world following upfront TURBT. The use of BCG in real-world clinical practice is largely consistent with guidelines with regards to the use of BCG induction therapy, which was used in all patients in the majority of studies. However, the use of maintenance therapy is more variable and less consistent, with less than a quarter of studies reporting that all high-risk patients received $\mathrm{BCG}$ maintenance therapy. Overall, BCG was found to be the mainstay therapy in HRNMIBC in the real-world setting, with other therapies including mitomycin $\mathrm{C}$, chemotherapy, and surgery used less frequently and less consistently. There is a wide variation in treatment patterns indicating that the realworld clinical management of HR-NMIBC is not standardized.

BCG is an effective therapy, and patients receiving maintenance $\mathrm{BCG}$ have a lower risk of recurrence and disease progression than those only receiving induction therapy or re-TURBT, no further treatment, or not completing maintenance therapy. ${ }^{20,34,52}$ However, the improvements reported with BCG in terms of survival, TTR, and TTP vary across studies. This may be due to differences in the proportion of patients with non-primary tumors and in those completing maintenance BCG. ${ }^{34,78,87}$ Patients undergoing early radical cystectomy have a significantly lower risk of mortality than initial local treatment with intravesical $\mathrm{BCG},{ }^{67}$ yet no difference in cancer-specific mortality was found between up-front or delayed cystectomy after BCG. ${ }^{71}$ High rates of disease recurrence in high-risk 

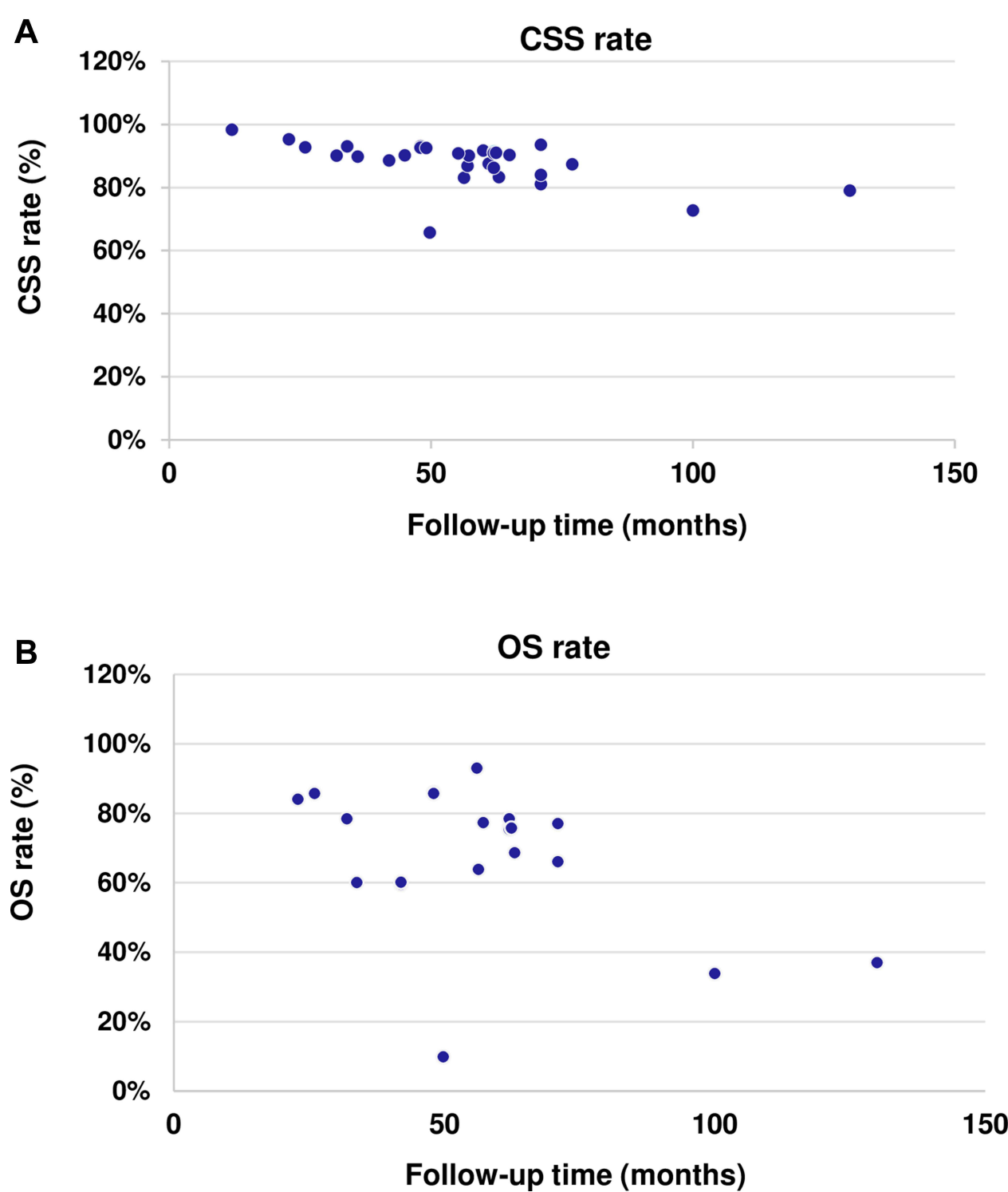

Figure 5 CSS and OS rates by follow-up time (months) in HR-NMIBC. Follow-up time in HR-NMIBC in (A) CSS and (B) OS rates. Each blue dot corresponds to a value from an individual study.

Notes: CSS rates $17,20-23,27-29,32,33,40-42,44,46,47,49,51,52,66,68,70,74,83,86-88,97-99,110$ and OS rates ${ }^{23,27,28,32,33,37,47,49,51,58,66,69,70,74,83,86-88,97-99}$ are presented as reported by individual study, they do not reflect weighted averages.

Abbreviations: CSS, cancer-specific survival; HR-NMIBC, high-risk non-muscle invasive bladder cancer; OS, overall survival.

patients are associated with lower 5-year RFS and a high disease burden, based on the need to undergo repeated TURBT or radical cystectomy. ${ }^{27,46,54}$

Overall, disease recurrence and survival outcomes seen in the real-world setting are heterogeneous. This heterogeneity may be influenced by inconsistent use of treatments in clinical practice, variations in the patient populations included in studies, as well as differences in the methodology and data sources used across studies. RWE studies comparing the efficacy of intravesical BCG and chemo- or immunotherapy are scarce, and outcomes reported to date are variable. There is a need to better understand the factors associated with the use of BCG and other intravesical therapies or surgical procedures in HR-NMIBC, as well as their effectiveness in the real-world.

\section{Limitations}

The generalization of results may be limited by the heterogenous nature of real-world data due to variations across studies in their design, patient populations, data collection, reporting, and methodologies. The high variability of 
population characteristics and therapeutic strategies made it difficult to derive average scores for key efficacy outcomes of CSS, OS, PFS, and RFS in HR-NMIBC, so results were instead reported by the individual studies. Another key factor contributing to data heterogeneity is the variability of criteria used to define high-risk disease in RWE studies. For this reason, all outcomes should be interpreted in the context of the clinical characteristics (ie, tumor stage and grade, response to prior therapy, tumor characteristics) of the HR-NMIBC population. Further, the observational nature of RWE means that caution should be exercized when comparing outcomes across different studies due to differences in the representativeness of the patient populations and differences in study design.

\section{Conclusion}

BCG treatment rates and survival outcomes in HRNMIBC vary in the real world, with better survival seen in patients completing maintenance $\mathrm{BCG}$, in those responding to treatment generally, and not progressing to muscle-invasive disease. There is a need to better understand the factors associated with BCG use and discontinuation and to develop an effective treatment that improves outcomes in HR-NMIBC.

\section{Acknowledgments}

The authors would like to acknowledge Stephanie Oldham at Purple Squirrel Economics for providing editorial support for the manuscript, which was funded by Pfizer.

\section{Funding}

This study was funded by Pfizer.

\section{Disclosure}

The following authors were Pfizer employees at the time the study was conducted: Elizabeth Masters and Slaven Sikirica. Debduth B Pijush was an employee of Atrium Staffing, which was a paid contractor to Pfizer in connection with the development of this manuscript. Mihaela Georgiana Musat, Christina Soeun Kwon, and Anna Forsythe are employees of Purple Squirrel Economics, which was a paid consultant to Pfizer in connection with the development of this manuscript. The authors report no other conflicts of interest in this work.

\section{References}

1. Saginala K, Barsouk A, Aluru JS, Rawla P, Padala SA, Barsouk A. Epidemiology of bladder cancer. Med Sci. 2020;8(1):15. doi:10.3390/ medsci8010015
2. National Cancer Institute. Cancer of the urinary bladder - Cancer stat facts. SEER; 2020. Available from: https://seer.cancer.gov/ statfacts/html/urinb.html. Accessed September 28, 2020.

3. NCCN. Bladder cancer, Version 6.2020, NCCN clinical practice guidelines in oncology. JNCCN; 2020. Available from: https:// www.nccn.org/professionals/physician_gls/pdf/bladder_blocks. pdf. Accessed December 21, 2021.

4. Babjuk M, Burger M, Comperat E, et al. EAU guidelines on nonmuscle-invasive bladder cancer (TaT1 and CIS); 2020:1-54.

5. Mbeutcha A, Lucca I, Mathieu R, Lotan Y, Shariat SF. Current status of urinary biomarkers for detection and surveillance of bladder cancer. Urol Clin North Am. 2016;43(1):47-62. doi:10.1016/j.ucl.2015.08.005

6. Anastasiadis A, Cordeiro E, Bus MT, Alivizatos G, de la Rosette JJ, de Reijke TM. Follow-up procedures for non-muscle-invasive bladder cancer: an update. Expert Rev Anticancer Ther. 2012;12 (9):1229-1241. doi:10.1586/era.12.98

7. Shen P-L, Lin M-E, Hong Y-K, He X-J. Bladder preservation approach versus radical cystectomy for high-grade non-muscleinvasive bladder cancer: a meta-analysis of cohort studies. World J Surg Oncol. 2018;16(1):197. doi:10.1186/s12957-0181497-0

8. Chang SS, Boorjian SA, Chou R, et al. Diagnosis and treatment of non-muscle invasive Bladder cancer: AUA/SUO Guideline [amended 2020]. J Urol. 2016;196(4):1021-1029. doi:10.1016/j. juro.2016.06.049

9. Pan -C-C, Chang Y-H. The 2004 World Health Organization/ International Society of Urological Pathology classification system for non-muscle-invasive bladder cancer. Urol Sci. 2013;24 (3):96-100. doi:10.1016/j.urols.2013.06.006

10. Sylvester RJ, van der Meijden APM, Oosterlinck W, et al. Predicting recurrence and progression in individual patients with stage Ta T1 bladder cancer using EORTC risk tables: a combined analysis of 2596 patients from seven EORTC trials. Eur Urol. 2006;49(3):466-477. doi:10.1016/j.eururo.2005.12.031

11. Fernandez-Gomez J, Madero R, Solsona E, et al. Predicting nonmuscle invasive bladder cancer recurrence and progression in patients treated with bacillus Calmette-Guerin: the CUETO scoring model. $J$ Urol. 2009;182(5):2195-2203. doi:10.1016/j.juro.2009.07.016

12. Centre for Reviews and Dissemination, ed. CRD's Guidance for Undertaking Reviews in Health Care. 3rd ed. CRD: University of York; 2009.

13. NICE. Methods for the Development of NICE Public Health Guidance. 3rd ed. National Institute for Health and Care Excellence; 2012. Available from: https://www.ncbi.nlm.nih.gov/books/ NBK395862/pdf/Bookshelf_NBK395862.pdf. Accessed December $21,2021$.

14. Higgins J, Thomas J, Chandler J, Cumpston M. Cochrane Handbook for Systematic Reviews of Interventions | Cochrane Training. In: 6.0. John Wiley \& Sons; 2019. Available from: https://training.cochrane.org/handbook/current. Accessed December 21, 2021.

15. Moher D, Liberati A, Tetzlaff J, Altman DG; PRISMA Group. Preferred reporting items for systematic reviews and meta-analyses: the PRISMA statement. PLoS Med. 2009;6(7):e1000097. doi:10.1371/journal.pmed.1000097

16. Al-Hogbani M, Gilbert S, Lodde M, Fradet Y, Toren P. Does 5alpha reductase inhibitor use improve the efficacy of intravesical Bacille Calmette-Guerin (BCG) for non-muscle invasive bladder cancer? Bladder Cancer. 2020;6(1):63-69. doi:10.3233/BLC190262

17. Alhogbani MM, Picard JA, Fassi-Fehri MH, Badet JL, Colombel CM. Prognostic impact of Bacillus Calmette-Guerin interruption at the time of induction and consolidation. Urol Ann. 2017;9 (4):315-320. doi:10.4103/UA.UA_115_17 
18. Bangash H, Lozinskiy M, Hayne D. Management of high risk nonmuscle invasive bladder cancer: Is re-resection always essential? BJU Int. 2017;119(Supplement2):18. doi:10.1111/bju.13750

19. Bilski K, Kozikowski M, Skrzypczyk MA, et al. No gender diversities in outcomes in patients diagnosed with non-muscle invasive, high-risk bladder cancer treated with early second resection and BCG - A multicenter analysis. Eur Urol Suppl. 2019;18(2):e2409.

20. Calo B, Di Nauta M, Mancini V, Hoznek A, Cormio L, Carrieri G. Treating high-grade T1 bladder cancer in the elderly. Is intravesical instillation of BCG worth? J Gerontol Geriatr. 2018;2018 (4):183-188.

21. Calo B, Chirico M, Fortunato F, et al. Is repeat transurethral resection always needed in high-grade T1 bladder cancer? Front Oncol. 2019;9:465. doi:10.3389/fonc.2019.00465

22. Calo B, Sanguedolce F, Fortunato F, et al. The impact of age on intravesical instillation of Bacille Calmette-Guerin treatment in patients with high-grade T1 bladder cancer. Medicine. 2019;98 (31):e16223. doi:10.1097/MD.0000000000016223

23. Cantiello F, Russo GI, Vartolomei MD, et al. Systemic inflammatory markers and oncologic outcomes in patients with high-risk non-muscle-invasive urothelial bladder cancer. Eur Urol Oncol. 2018;1(5):403-410. doi:10.1016/j.euo.2018.06.006

24. Cho J, Edwards S, Kinnear N, O’Callaghan M, Chong M, Foreman D. How effective is BCG at eradicating Carcinoma In Situ (CIS) in a South Australian population? BJU Int. 2015;115 (SUPPL 4):4. doi:10.1111/bju.13072

25. Cohen D, Hogan M, Palmer A, et al. BCG efficacy differs according to the strain used-Implications in an era of BCG shortages. BJU Int. 2015;115(Supplement 7):74. doi:10.1111/ bju. 13136

26. Dal Moro F, Bovo A, Crestani A, Vettor R, Gardiman MP, Zattoni F. Effect of hypertension on outcomes of high-risk patients after BCG-treated bladder cancer: a single-institution long follow-up cohort study. Medicine. 2015;94(9):e589. doi:10.1097/ MD.0000000000000589

27. Ferro M, Vartolomei MD, Cantiello F, et al. High-grade T1 on retransurethral resection after initial high-grade T1 confers worse oncological outcomes: results of a multi-institutional study. Urol Int. 2018;101(1):7-15. doi:10.1159/000490765

28. Ferro M, Vartolomei MD, Russo GI, et al. An increased body mass index is associated with a worse prognosis in patients administered BCG immunotherapy for T1 bladder cancer. World J Urol. 2019;37(3):507-514. doi:10.1007/s00345-018-2397-1

29. Ferro M, Di Lorenzo G, Vartolomei MD, et al. Absolute basophil count is associated with time to recurrence in patients with highgrade T1 bladder cancer receiving bacillus Calmette-Guerin after transurethral resection of the bladder tumor. World J Urol. 2019;38(1):143-150. doi:10.1007/s00345-019-02754-2

30. Gan C, Amery S, Chatterton K, Khan MS, Thomas K, O'Brien T. Sequential bacillus Calmette-Guerin/Electromotive drug administration of mitomycin $\mathrm{C}$ as the standard intravesical regimen in high risk nonmuscle invasive bladder cancer: 2-year outcomes. $J$ Urol. 2016;195(6):1697-1703. doi:10.1016/j.juro.2016.01.103

31. Golabek T, Palou J, Rodriguez O, Gaya JM, Breda A, Villavicencio H. Is it possible to stop follow-up of patients with primary T1G3 urothelial carcinoma of the bladder managed with intravesical bacille Calmette-Guerin immunotherapy? World $J$ Urol. 2017;35(2):237-243. doi:10.1007/s00345-016-1856-9

32. Gontero P, Sylvester R, Pisano F, et al. Prognostic factors and risk groups in T1G3 non-muscle-invasive bladder cancer patients initially treated with Bacillus Calmette-Guerin: results of a retrospective multicenter study of 2451 patients. Eur Urol. 2015;67 (1):74-82. doi:10.1016/j.eururo.2014.06.040
33. Gontero P, Sylvester R, Pisano F, et al. The impact of re-transurethral resection on clinical outcomes in a large multicentre cohort of patients with T1 high-grade/Grade 3 bladder cancer treated with bacille Calmette-Guerin. BJU Int. 2016;118(1):44-52. doi:10.1111/bju.13354

34. Guerrero-Ramos F, Lara-Isla A, Justo-Quintas J, Duarte-Ojeda JM, de la Rosa-kehrmann F, Villacampa-Auba F. Adjuvant intravesical treatment for nonmuscle invasive bladder cancer: the importance of the strain and maintenance. Actas Urol Esp. 2017;41(9):590-595. doi:10.1016/j.acuro.2017.03.003

35. Herr H. Does asymptomatic bacteriuria affect the response to intravesical bacillus Calmette-Guerin? Int J Urol. 2020;27 (1):72-74. doi:10.1111/iju.14139

36. Hofbauer SL, Shariat SF, Chade DC, et al. The Moreau strain of Bacillus Calmette-Guerin (BCG) for high-risk non-muscle invasive bladder cancer: an alternative during worldwide BCG shortage? Urol Int. 2016;96(1):46-50. doi:10.1159/000440701

37. Holz S, Albisinni S, Gilsoul J, et al. Risk factor assessment in highrisk, bacillus Calmette-Guerin-treated, non-muscle-invasive bladder cancer. Res Rep Urol. 2017;9:195-202. doi:10.2147/RRU.S143865

38. Kamat AM, Briggman J, Urbauer DL, et al. Cytokine Panel for Response to Intravesical Therapy (CyPRIT): nomogram of changes in urinary cytokine levels predicts patient response to bacillus Calmette-Guerin. Eur Urol. 2016;69(2):197-200. doi:10.1016/j.eururo.2015.06.023

39. Kimura S, Soria F, D'Andrea D, et al. Prognostic value of serum cholinesterase in non-muscle-invasive bladder cancer. Clin Genitourin Cancer. 2018;16(6):e1123-e1132. doi:10.1016/j. clgc.2018.07.002

40. Krajewski W, Matuszewski M, Poletajew S, Grzegrzolka J, Zdrojowy R, Kolodziej A. Are there differences in toxicity and efficacy between various bacillus Calmette-Guerin strains in bladder cancer patients? Analysis of 844 patients. Urol Int. 2018;101 (3):277-284. doi:10.1159/000492722

41. Krajewski W, Zdrojowy R, Koscielska-Kasprzak K, et al. Does restaging transurethral resection of bladder tumour influence outcomes in patients treated with BCG immunotherapy? 491 cases in 20 years' experience. Wideochir Inne Tech Maloinwazyjne. 2019;14(2):284-296. doi:10.5114/wiitm.2018.79993

42. Krajewski W, Rodriguez Faba O, Breda A, et al. Analysis of age influence on oncological results and toxicity of BCG immunotherapy in non-muscle invasive bladder cancer. World J Urol. 2020;38 (12):3177-3182. doi:10.1007/s00345-020-03130-1

43. Krajewski W, Zdrojowy R, Dembowski J, et al. The optimal timing of restaging resection before introduction of bacillus Calmette-Guerin immunotherapy in patients with high-risk nonmuscle-invasive bladder cancer. Urol Int. 2019;102(1):60-68. doi:10.1159/000491642

44. Krajewski W, Zdrojowy R, Grzegolka J, et al. Does Mantoux test result predicts BCG immunotherapy efficiency and severe toxicity in non-muscle invasive bladder cancer. Urol j. 2019;16(5):458462. doi:10.22037/uj.v0i0.4542

45. Lenis AT, Donin NM, Litwin MS, et al. Association between number of endoscopic resections and utilization of bacillus Calmette-Guerin therapy for patients with high-grade, non-muscle-invasive bladder cancer. Clin Genitourin Cancer. 2017;15(1): e25-e31. doi:10.1016/j.clgc.2016.06.014

46. Li R, Metcalfe MJ, Tabayoyong WB, et al. Using grade of recurrent tumor to guide further therapy while on bacillus Calmette-Guerin: low-grade recurrences are not benign. Eur Urol Oncol. 2019;2(3):286-293. doi:10.1016/j. euo.2018.08.013 
47. Metcalfe MJ, Ferguson JE, Li R, et al. Impact of high-risk features and effect of neoadjuvant chemotherapy in urothelial cancer patients with invasion into the lamina propria on transurethral resection in the absence of deep muscle invasion. Eur Urol Focus. 2017;3(6):577-583. doi:10.1016/j.euf.2017.06.004

48. Munari E, Chaux A, Maldonado L, et al. Cyclin A1 expression predicts progression in pT1 urothelial carcinoma of bladder: a tissue microarray study of 149 patients treated by transurethral resection. Histopathology. 2015;66(2):262-269. doi:10.1111/ his. 12499

49. Nicolazzo C, Busetto GM, Gradilone A, et al. Circulating tumor cells identify patients with super-high-risk non-muscle-invasive bladder cancer: updated outcome analysis of a prospective singlecenter trial. Oncologist. 2019;24(5):612-616. doi:10.1634/theoncologist.2018-0784

50. Novotny V, Froehner M, Ollig J, Koch R, Zastrow S, Wirth MP. Impact of adjuvant intravesical bacillus Calmette-Guerin treatment on patients with high-grade $\mathrm{T} 1$ bladder cancer. Urol Int. 2016;96(2):136-141. doi:10.1159/000443705

51. Palou J, Pisano F, Sylvester R, et al. Recurrence, progression and cancer-specific mortality according to stage at re-TUR in T1G3 bladder cancer patients treated with BCG: not as bad as previously thought. World $J$ Urol. 2018;36(10):1621-1627. doi:10.1007/s00345-018-2299-2

52. Palou-Redorta J, Solsona E, Angulo J, et al. Retrospective study of various conservative treatment options with bacille CalmetteGuerin in bladder urothelial carcinoma T1G3: maintenance therapy. Actas Urol Esp. 2016;40(6):370-377. doi:10.1016/j. acuro.2015.12.009

53. Patriarca C, Hurle R, Moschini M, et al. Usefulness of pT1 substaging in papillary urothelial bladder carcinoma. Diagn Pathol. 2016;11:6. doi:10.1186/s13000-016-0466-6

54. Pellucchi F, Freschi M, Moschini M, et al. Oncological predictive value of the 2004 World Health Organisation grading classification in primary $\mathrm{T} 1$ non-muscle-invasive bladder cancer. A step forward or back? BJU Int. 2015;115(2):267-273. doi:10.1111/ bju. 12666

55. Poletajew S, Biernacki R, Buraczynski P, et al. Predictors and prognostic implications of clinical decisions in patients with primary high-risk non-muscle-invasive bladder cancer - results of a cross country retrospective study. Neoplasma. 2018;65 (1):147-152. doi:10.4149/neo_2018_170217N123

56. Racioppi M, Di Gianfrancesco L, Ragonese M, Palermo G, Sacco E, Bassi P. The challenges of Bacillus of Calmette-Guerin (BCG) therapy for high risk non muscle invasive bladder cancer treatment in older patients. J Geriatr Oncol. 2018;9(5):507-512. doi:10.1016/j.jgo.2018.03.020

57. Racioppi M, Di Gianfrancesco L, Ragonese M, Palermo G, Sacco E, Bassi PF. Can Neutrophil-to-Lymphocyte ratio predict the response to BCG in high-risk non muscle invasive bladder cancer? Int Braz J Urol. 2019;45(2):315-324. doi:10.1590/S16775538.IBJU.2018.0249

58. Ravvaz K, Weissert JA, Downs TM. American urological association nonmuscle invasive bladder cancer risk model validationshould patient age be added to the risk model? J Urol. 2019;202 (4):682-688. doi:10.1097/JU.0000000000000389

59. Richards KA, Lin S-W, Chuo C-Y, et al. Increased bacillus Calmette-Guerin treatment intensity associated with improved outcomes in elderly patients with non-muscle-invasive bladder cancer. J Urol. 2019;201(4 Supplement 1):e314. doi:10.1097/01. JU.0000555581.13406.45

60. Rieken M, Shariat SF, Kluth L, et al. Comparison of the EORTC tables and the EAU categories for risk stratification of patients with nonmuscle-invasive bladder cancer. Urol Oncol. 2018;36 (1):8.e17-8.e24. doi:10.1016/j.urolonc.2017.08.027
61. Roumiguie M, Comperat E, Neuzillet Y, et al. PD-L1/PD-1 expression as a predictor of response to BCG in patients with high-risk nonmuscle invasive bladder cancer. J Clin Oncol. 2019;37(Supplement 15):4550. doi:10.1200/JCO.2019.37.15_suppl.4550

62. Sekar RR, Brisbane WG, Holt SK, et al. Diabetes severity and metformin are associated with intravesical bacillus Calmette-Guerin outcomes in non muscle invasive bladder cancer. J Urol. 2019;201(4 Supplement 1):e229. doi:10.1097/01.JU.0000555389.67995.d9

63. Serretta V, Scalici Gesolfo C, Alonge V, Cicero G, Moschini M, Colombo R. Does the Compliance to Intravesical BCG differ between common clinical practice and international multicentric trials? Urol Int. 2016;96(1):20-24. doi:10.1159/000430501

64. Sikic D, Breyer J, Hartmann A, et al. High androgen receptor mRNA expression is independently associated with prolonged cancer-specific and recurrence-free survival in stage T1 bladder cancer. Transl Oncol. 2017;10(3):340-345. doi:10.1016/j. tranon.2017.01.013

65. Soria F, Pisano F, Gontero P, et al. Predictors of oncological outcomes in T1G3 patients treated with BCG who undergo radical cystectomy. World J Urol. 2018;36(11):1775-1781. doi:10.1007/s00345-018-2450-0

66. Thiel T, Ryk C, Renstrom-Koskela L, et al. Intravesical BCG treatment causes a long-lasting reduction of recurrence and progression in patients with high-risk non-muscle-invasive bladder cancer. World J Urol. 2019;37(1):155-163. doi:10.1007/s00345018-2375-7

67. Tully KH, Roghmann F, Noldus J, et al. Quantifying the overall survival benefit with early radical cystectomy for patients with histologically confirmed T1 non-muscle-invasive bladder cancer. Clin Genitourin Cancer. 2020;18(6):e651-e659. doi:10.1016/j. clgc.2020.03.013

68. Unda-Urzaiz M, Cozar-Olmos JM, Minana-Lopez B, et al. Safety and efficacy of various strains of bacille Calmette-Guerin in the treatment of bladder tumours in standard clinical practice. Actas Urol Esp. 2018;42(4):238-248. doi:10.1016/j.acuro.2017.10.003

69. Vartolomei MD, Ferro M, Cantiello F, et al. Validation of neutrophil-to-lymphocyte ratio in a multi-institutional cohort of patients with T1G3 non-muscle-invasive bladder cancer. Clin Genitourin Cancer. 2018;16(6):445-452. doi:10.1016/j. clgc.2018.07.003

70. Vetterlein MW, Gild P, Marks P, et al. Evaluating guideline adherence for T1 bladder cancer treatment and surveillance: a retrospective German multicenter observation. Urol Int. 2018;101 (3):285-292. doi:10.1159/000493369

71. Wang EY-H, Larsson U, Gardmark T, Malmstrom P-U. What is the outcome after initial or delayed cystectomy for high-risk nonmuscle invasive bladder cancer? A Swedish Nationwide analysis. Scand J Urol. 2019;53(Supplement 221):35. doi:10.1080/ 21681805.2019.1619285

72. Weiss BE, Pietzak EJ, Wein AJ, Malkowicz SB, Guzzo TJ. Single instillation of mitomycin $\mathrm{C}$ plus bacillus Calmette-Guerin (BCG) versus BCG alone in high grade non-muscle invasive bladder cancer. Can J Urol. 2015;22(4):7876-7881.

73. Williams SB, Howard L, Foster M, et al. Long-term outcomes among BCG-treated high-risk non-muscle invasive bladder cancer patients in an equal access setting. American Society of Clinical Oncology; 2020. Available from: https://meetinglibrary. asco.org/record/191244/abstract. Accessed December 21, 2021.

74. Witjes JA, Dalbagni G, Karnes RJ, et al. The efficacy of BCG TICE and BCG Connaught in a cohort of 2,099 patients with T1G3 non-muscle-invasive bladder cancer. Urol Oncol. 2016;34 (11):484.e19-484.e25. doi:10.1016/j.urolonc.2016.05.033

75. Witjes JA, Dalbagni G, Shariat S, et al. The impact of different BCG strains on outcome in a large cohort of T1G3 patients treated with BCG. Eur Urol Suppl. 2015;14(2):e948-a. 
76. Wong RL, Holt SK, Guo A, Gore JL. Intravesical therapy and risk of cystectomy and bladder cancer death after BCG fails. American Society of Clinical Oncology; 2020. Available from: https://meetinglibrary.asco.org/record/191284/abstract. Accessed December 21, 2021.

77. Caputo JM, Moran G, Muller B, Keller AT, Li G, Anderson CB. The management of newly-diagnosed non-muscle invasive bladder cancer in veterans integrated services network 02 of the veterans health administration. Mil Med. 2020;185(1-2):276281. doi:10.1093/milmed/usz166

78. Mitrakas LP, Zachos IV, Tzortzis VP, et al. Previous bladder cancer history in patients with high-risk, non-muscle-invasive bladder cancer correlates with recurrence and progression: implications of natural history. Cancer Res Treat. 2015;47(3):495-500. doi: $10.4143 /$ crt.2014.050

79. Austin T, Robinson R, Wilby D, Hall S, Hodgson D. Day case primary trans-urethral resection of bladder tumour (TURBT) as standard in a single UK centre. Should this be the new norm? $J$ Clini Urol. 2020;13(4):273-278. doi:10.1177/2051415819890479

80. Bello AP, Villacampa F, Goizueta JD, et al. Chemohyperthermia with mitomycin $\mathrm{c}$ and combat system a new alternative to bcb in high risk non muscle invasive bladder cancer? J Urol. 2018;199(4 Supplement 1):e1119.

81. Canepa G, Campodonico F, Capponi G, et al. Intravesical thermochemotherapy with mytomicin $\mathrm{C}$ as a treatment for high-and intermediate-risk non-muscle invasive bladder cancer: nine year single centre experience on activity, tolerability and technical aspects. Anticancer Res. 2015;35(6):3716-3717.

82. Check DK, Aaronson DS, Nielsen ME, et al. Perioperative intravesical chemotherapy for patients with non-muscle-invasive bladder cancer: understanding the extent of and sources of variation in guideline-recommended use. Urology. 2019;124(wsy, 0366151):107-112. doi:10.1016/j.urology.2018.10.016

83. Breyer J, Wirtz RM, Erben P, et al. FOXM1 overexpression is associated with adverse outcome and predicts response to intravesical instillation therapy in stage pT1 non-muscle-invasive bladder cancer. BJU Int. 2019;123(1):187-196. doi:10.1111/ bju. 14525

84. Ferro M, Lorenzo GD, Buonerba C, et al. Predictors of residual T1 high grade on re-transurethral resection in a large multi-institutional cohort of patients with primary T1 high-grade/grade 3 bladder cancer. J Cancer. 2018;9(22):4250-4254. doi:10.7150/ jca. 26129

85. Giulianelli R, Gentile BC, Mirabile G, et al. Narrow band imaging reduces persistence of cancer in patients with $\mathrm{pT} 1$ high grade bladder cancer. Eur J Surg Oncol. 2019;45(3):466-470. doi:10.1016/j.ejso.2018.06.004

86. Gordon PC, Thomas F, Noon AP, Rosario DJ, Catto JWF. Longterm outcomes from re-resection for high-risk non-muscle-invasive bladder cancer: a potential to rationalize use. Eur Urol Focus. 2019;5(4):650-657. doi:10.1016/j.euf.2017.10.004

87. Orsola A, Werner L, de Torres I, et al. Reexamining treatment of high-grade T1 bladder cancer according to depth of lamina propria invasion: a prospective trial of 200 patients. $\mathrm{Br} J$ Cancer. 2015;112(3):468-474. doi:10.1038/bjc.2014.633

88. Otto W, van Rhijn BW, Breyer J, et al. Infiltrative lamina propria invasion pattern as an independent predictor for cancer-specific and overall survival of instillation treatment-naive stage T1 highgrade urothelial bladder cancer. Int J Urol. 2018;25(5):442-449. doi:10.1111/iju.13532

89. Soria F, D'Andrea D, Moschini M, et al. Predictive factors of the absence of residual disease at repeated transurethral resection of the bladder. Is there a possibility to avoid it in well-selected patients? Urol Oncol Semin Orig Investig. 2020;38(3):77. doi:10.1016/j.urolonc.2019.08.010
90. Zapala P, Dybowski B, Poletajew S, Bialek L, Niewczas A, Radziszewski P. Clinical rationale and safety of restaging transurethral resection in indication-stratified patients with high-risk non-muscle-invasive bladder cancer. World J Surg Oncol. 2018;16(1):6. doi:10.1186/s12957-018-1310-0

91. Amador BM, Samarska I, Bivalacqua T, Kates M, Matoso A. Outcome of unexpected prostatic urethral involvement at cystoprostatectomy for non-muscle invasive bladder cancer: implications for prostate sparing cystectomy. Mod Pathol. 2019;32(3):75.

92. Chamie K, Ballon-Landa E, Daskivich TJ, et al. Treatment and survival in patients with recurrent high-risk non-muscle-invasive bladder cancer. UROL ONCOL. 2015;33(1):20.e9-20.e17. doi:10.1016/j.urolonc.2014.08.016

93. Chang S, Martin K, Shaffer D, Guo A, Hadker N. PCN356 realworld evidence on patients with non-muscle invasive bladder cancer treated with BCG therapy. Value Health. 2020;23 (Supplement 1):S87. doi:10.1016/j.jval.2020.04.1812

94. Deuker M, Franziska Stolzenbach L, Rosiello G, et al. Radical cystectomy improves survival in patients with stage T1 squamous cell carcinoma and neuroendocrine carcinoma of the urinary bladder. Eur J Surg Oncol. 2020;47(2):463-469. doi:10.1016/j. ejso.2020.05.006

95. Ludecke G, Schafer L, Nativ O, et al. Radiofrequency induced hyperthermia chemotherapy (RIHTC) in high-risk non-muscle invasive bladder cancer (NMIBC): multiinstitutional, international outcome analysis of 271 treated patients with a follow-up time of more than 2 years. Eur Urol Suppl. 2015;14(2):e949e949a. doi:10.1016/S1569-9056(15)60937-X

96. Matulewicz RS, Frainey BT, Oberlin DT, Meeks JJ. High-risk of adverse pathologic features in patients with clinical T1 high-grade bladder cancer undergoing radical cystectomy. J Natl Compr Cancer Netw. 2016;14(11):1403-1411. doi:10.6004/jnccn.2016.0150

97. Steinberg RL, Thomas LJ, Brooks N, et al. Multi-institution evaluation of sequential gemcitabine and docetaxel as rescue therapy for nonmuscle invasive bladder cancer. $J$ Urol. 2020;203(5):902-909. doi:10.1097/JU.0000000000000688

98. van de Putte EEF, Bosschieter J, van der Kwast TH, et al. The World Health Organization 1973 classification system for grade is an important prognosticator in T1 non-muscle-invasive bladder cancer. BJU Int. 2018;122(6):978-985. doi:10.1111/bju.14238

99. Brant A, Daniels M, Chappidi MR, et al. Prognostic implications of prostatic urethral involvement in non-muscle-invasive bladder cancer. World J Urol. 2019;37(12):2683-2689. doi:10.1007/ s00345-019-02673-2

100. Lenis AT, Lec PM, Michel J, et al. Predictors of adequate lymph node dissection in patients with non-muscle invasive bladder cancer undergoing radical cystectomy and effect on survival. Urol Oncol Semin Orig Investig. 2020;38:796-e7. doi:10.1016/j. urolonc.2020.04.027

101. Minardi D, Milanese G, Parri G, Lacetera V, Muzzonigro G. Nonmuscle invasive high grade urothelial carcinoma of the bladder. Which factors can influence understaging at the time of radical cystectomy? Arch Ital Urol Androl. 2016;88(1):13-16. doi:10.4081/ aiua.2016.1.13

102. Pang KH, Thomas F, Novara G, et al. The impact of centralised services on metric reflecting high-quality performance: outcomes from 1110 consecutive radical cystectomies at a single centre. Eur Urol Focus. 2020;7(3):554-565. doi:10.1016/j.euf.2020.05.011

103. Guerrero-Ramos F, Lara-Isla A, Justo-Quintas J, Duarte-Ojeda JM, de la Rosa-kehrmann F, Villacampa-Auba F. Tratamiento adyuvante intravesical en cancer de vejiga no musculo invasivo: importancia de la cepa y el mantenimiento, Adjuvant intravesical treatment for nonmuscle invasive bladder cancer: the importance of the strain and maintenance. Actas Urol Esp. 2017;41(9):590595. doi:10.1016/j.acuro.2017.03.003 
104. Soria F, D’Andrea D, Abufaraj M, et al. Stratification of intermediate-risk non-muscle-invasive bladder cancer patients: implications for adjuvant therapies. Eur Urol Focus. 2020;7(3):566573. doi:10.1016/j.euf.2020.05.004

105. Avgeris M, Tsilimantou A, Levis PK, et al. Loss of GAS5 tumour suppressor lncRNA: an independent molecular cancer biomarker for short-term relapse and progression in bladder cancer patients. $\mathrm{Br} J$ Cancer. 2018;119(12):1477-1486. doi:10.1038/s41416-018-0320-6

106. Avgeris M, Tsilimantou A, Levis PK, et al. Unraveling UCA1 IncRNA prognostic utility in urothelial bladder cancer. Carcinogenesis. 2019;40(8):965-974. doi:10.1093/carcin/bgz045

107. Demkiw S, Mow T, Duggan G, Goad J, Wong L-M. Predicting recurrence and progression in Australian patients with nonmuscle-invasive bladder cancer using the EORTC scoring model. BJU Int. 2015;115(SUPPL 4):56. doi:10.1111/bju.13073

108. Lacombe L, Fradet V, Levesque E, et al. Phase II drug-metabolizing polymorphisms and smoking predict recurrence of non-muscle- invasive bladder cancer: a gene-smoking interaction. Cancer Prev Res. 2016;9(2):189-195. doi:10.1158/1940-6207.CAPR-15-0069
109. Seo M, Langabeer JR. Demographic and survivorship disparities in non-muscle-invasive bladder cancer in the United States. J Prev Med Public Health. 2018;51(5):242-247. doi:10.3961/jpmph.18.092

110. Rezaee ME, Lynch KE, Li Z, et al. The impact of low- versus high-intensity surveillance cystoscopy on surgical care and cancer outcomes in patients with high-risk non-muscle-invasive bladder cancer (NMIBC). PLoS One. 2020;15(3):e0230417. doi:10.1371/ journal.pone.0230417

111. Jeglinschi S, Schirmann A, Durand M, Sanchez S, Larre S, Leon P. Factors affecting guideline adherence in the initial treatment of non-muscle invasive bladder cancer: retrospective study in a French peripheral hospital. Prog Urol. 2020;30(1):26-34. doi:10.1016/j.purol.2019.11.003

112. Lamm DL, Blumenstein BA, Crissman JD, et al. Maintenance bacillus Calmette-Guerin immunotherapy for recurrent TA, T1 and carcinoma in situ transitional cell carcinoma of the bladder: a randomized Southwest Oncology Group Study. J Urol. 2000;163(4):1124-1129. doi:10.1016/S0022-5347(05)67707-5

\section{Publish your work in this journal}

ClinicoEconomics and Outcomes Research is an international, peerreviewed open-access journal focusing on Health Technology Assessment, Pharmacoeconomics and Outcomes Research in the areas of diagnosis, medical devices, and clinical, surgical and pharmacological intervention. The economic impact of health policy and health systems organization also constitute important areas of coverage. The manuscript management system is completely online and includes a very quick and fair peer-review system, which is all easy to use. Visit http://www.dovepress.com/testimonials.php to read real quotes from published authors. 